Ahmad et al., Afr. J. Infect. Dis. (2015) 9(2): 29- 31

http://dx.doi.org/10.4314/ajid.v9i2.2

PREVALENCE OF MALARIA INFECTION IN CHILDREN ATTENDING EMERGENCY PAEDIATRICS UNIT OF USMANU DANFODIYO UNIVERSITY TEACHING HOSPITAL, SOKOTO - NIGERIA

\author{
${ }^{1}$ Ahmad, A. E., ${ }^{2}$ Sheyin, Z., ${ }^{3}$ Kabir, M., ${ }^{3}$ Nuhu, A., ${ }^{3}$ Garba, M. K., ${ }^{3}$ Nata'ala, U. \\ ${ }^{1}$ Dean's Office, Faculty of Medicine, Ahmadu Bello University Zaria - Nigeria. ${ }^{2}$ Hajiya Gambo Sawaba General Hospital, \\ Zaria - Nigeria. ${ }^{3}$ Department of Medical Microbiology, Faculty of Medical Laboratory Sciences, Usmanu Danfodiyo \\ University, Sokoto - Nigeria. \\ *E-mail: a_rahmanzarx@yahoo.com,aahmad@abu.edu.ng
}

\begin{abstract}
Background: Malaria infection in children has been of concern in this part of the world - the sub-Saharan Africa. This study was undertaken to determine the prevalence of this deadly infection in children attending Usmanu Danfodiyo University Teaching Hospital (UDUTH) Sokoto.

Materials and Methods: One hundred and twenty four (124) capillary blood samples were collected from patients attending the Emergency Pediatrics Unit side laboratory. The 'gold standard' method was applied using Giemsa stain to carry out the investigation. Both thick and thin blood films were investigated for malaria parasite concentration and specie identification respectively.

Results: Out of the 124 samples collected, $82(66.13 \%)$ tested positive and $42(33.87 \%)$ were negative for malaria infection. A total of 49 (39.52\%) males and $33(26.61 \%)$ females were positive for the infection. Of all the positive samples children within the age range of $0-5$ years had the highest prevalence of $72(58.06 \%)$ while the other age group of $6-10$ years had a relatively lower prevalence of $10(8.07 \%)$. However, using Chi-square test of independence, statistical analyses suggest that there is no statistically significant association between the distribution of malaria infection and age or gender.

Conclusion P. falciparum accounted for about $(84.15 \%)$ of the cases of malaria infection in the study area.
\end{abstract}

Keywords: Malaria, children, prevalence, UDUTH, Chi-Square.

\title{
Introduction
}

Malarial parasites belong to the genus Plasmodium. Plasmodium is the only genus belonging to the family Plasmodiidae, order Haemosporida, class Coccidea, phylum Sporozoa (Apicomplexa). The genus contains over 125 species that cause malaria in mammals, reptiles and birds (Hommel and Gilles, 2006), with four species that cause malaria specifically in man. The species are Plasmodium falciparum which is widely distributed, mainly in the tropics; Plasmodium malariae which occurs sporadically in different parts of the world; Plasmodium vivax which has the widest distribution, extending through the tropics, subtropics and temperate zones and Plasmodium ovale which is mainly confined to Central West Africa and some South Pacific islands. P. vivax and P. falciparum together account for about (95\%), of human infection/s. (Ochei and Kolhatkar, 2000).

Four major determinants namely the parasite, the vector, the human host and the environment are relevant to the dynamics of malaria transmission (Hommel and Gilles, 2006). It is reviewed on the economic and social burden of malaria that where malaria prospers most, human societies have prospered least. The global distribution of per-capita gross domestic product shows a striking correlation between malaria and poverty, and malaria-endemic countries also have lower rates of economic growth. There are multiple channels by which malaria impedes development, including effects on fertility, population growth, saving and investment, worker productivity, absenteeism, premature mortality and Medical costs (Jeffrey and Pia, 2002).

According to the WHO (2004), malaria is currently endemic in more than 100 countries or territories, mainly in sub-Saharan Africa where Sokoto, the area for this study is located. Each year there are $300-500$ million clinical cases of malaria with $90 \%$ of them in Africa, resulting in $1.5-2.7$ million deaths, mostly children under 5 years (Cheesbrough, 2000). Consequently, Emergency Pediatrics Unit (EPU), is provided specifically in Usmanu Danfodiyo University Teaching Hospital to check the ever evolving malaria infection in children. This study determined the prevalence of malaria infection in children attending Usmanu Danfodiyo University Teaching Hospital Sokoto.

\section{Subjects and Method}

The area selected for this study was the metropolitan city of Sokoto, capital city of Sokoto State, which comprises Sokoto North, Sokoto South, Dange Shuni and Wamakko Local Government Areas. It is located in the Sudan Savanna belt of the North-Western zone of Nigeria, lying between longitude $05^{0} 11^{1}$ to $13^{0} 03^{1}$ East and latitude $13^{0} 00^{1}$ to $13^{0} 06^{1}$ North and covers an area of $60.33 \mathrm{~km}^{2}$, with the annual mean rainfall ranges between $500 \mathrm{~mm}$ to $1,300 \mathrm{~mm}$ (Iman, 2006). The subjects used for this study were mainly children of not more than 10 years of age, attending Pediatrics Unit of Usmanu Danfodiyo University Teaching Hospital Sokoto for their Medical check up from February through August. Specimens of the subjects were collected in Emergency Paediatrics Unit together with some bio-data which include age, sex, place of residence and whether the patient was under treatment or not. Patients in attendance, most if not all, are inhabitants of Sokoto metropolis. A total number of 124 patients were used as case study of which 68 were males and 56 were females. Two drops of capillary blood were collected on a clean grease-free glass slide; one for thick film and the other for thin film, both on the same slide. The slides were labeled and stained appropriately using Giemsa's staining technique (Cheesbrough, 2000). The blood films were examined microscopically using the 100x objective of the microscope. To be noted, for the purpose of this study, only presence or absence of the parasite was reported and no quantification was carried out. '1 to 10 parasites per 100 fields' was considered the minimum for positive indication (Cheesbrough, 2000). 


\section{Results}

Of the 124 capillary blood samples collected, $66.13 \%$ (82) tested positive for malaria of which $39.52 \%$ (49) were males and $26.61 \%$ (33) females. For both genders Wamakko has the highest prevalence of 28.23\% (35) while Dange Shuni, Sokoto South and Sokoto North were having $20.97 \%$ (26), $12.10 \%$ (15) and $1.61 \%$ (2) respectively. Others who were not based in Sokoto metropolis had 3.23\% (4), all as shown in Table 1.

Table 1: Distribution of malaria infection between the genders in the Local Governments in Sokoto metropolis

\begin{tabular}{|c|c|c|c|c|c|c|}
\hline \multirow{3}{*}{$\begin{array}{c}\text { Local } \\
\text { Government } \\
\text { Areas }\end{array}$} & \multicolumn{4}{|c|}{ Sex } & \multirow{2}{*}{\multicolumn{2}{|c|}{ Total }} \\
\hline & \multicolumn{2}{|c|}{ Males } & \multicolumn{2}{|c|}{ Females } & & \\
\hline & $\begin{array}{c}\text { No. } \\
\text { Examined }\end{array}$ & $\begin{array}{c}\text { No. } \\
\text { Positive } \\
(\%)\end{array}$ & $\begin{array}{c}\text { No. } \\
\text { Examined }\end{array}$ & $\begin{array}{c}\text { No. } \\
\text { Positive } \\
(\%)\end{array}$ & $\begin{array}{c}\text { No. } \\
\text { Examined }\end{array}$ & $\begin{array}{l}\text { No. } \\
\text { Positive } \\
(\%)\end{array}$ \\
\hline Sokoto North & 0 & $0(0.00)$ & 2 & $2(1.61)$ & 2 & $2(1.61)$ \\
\hline Sokoto South & 16 & $9(7.26)$ & 10 & $6(4.84)$ & 26 & $15(12.10)$ \\
\hline Wamakko & 26 & $22(17.74)$ & 23 & $13(10.48)$ & 49 & $35(28.23)$ \\
\hline Dange Shuni & 24 & $16(12.90)$ & 19 & $10(8.06)$ & 43 & $26(20.97)$ \\
\hline Others & 2 & $2(1.61)$ & 2 & $2(1.61)$ & 4 & $4(3.23)$ \\
\hline Total & 68 & $49(39.52)$ & 56 & $33(26.61)$ & 124 & $82(66.13)$ \\
\hline
\end{tabular}

The $0-5$ year age group for both genders recorded the highest prevalence of $58.06 \%$ (72) while the $6-10$ year age group recorded $8.07 \%$ (10) as shown in Table 2 .

Table 2: Distribution of malaria infection per gender and age groups among children

\begin{tabular}{|c|c|c|c|c|c|c|}
\hline \multirow{3}{*}{$\begin{array}{l}\text { Age Groups } \\
\text { (Yrs) }\end{array}$} & \multicolumn{4}{|c|}{ Sex } & \multirow{2}{*}{\multicolumn{2}{|c|}{ Total }} \\
\hline & \multicolumn{2}{|c|}{ Males } & \multicolumn{2}{|c|}{ Females } & & \\
\hline & $\begin{array}{c}\text { No. } \\
\text { Examined }\end{array}$ & $\begin{array}{c}\text { No. } \\
\text { Positive } \\
(\%)\end{array}$ & $\begin{array}{c}\text { No. } \\
\text { Examined }\end{array}$ & $\begin{array}{c}\text { No. } \\
\text { Positive } \\
(\%)\end{array}$ & No. Examined & $\begin{array}{l}\text { No. } \\
\text { Positive } \\
(\%)\end{array}$ \\
\hline $0-5$ & 61 & 43 (34.68) & 50 & $29(23.38)$ & 111 & $72(58.06)$ \\
\hline $6-10$ & 7 & $6(4.84)$ & 6 & $4(3.23)$ & 13 & $10(8.07)$ \\
\hline Total & 68 & $49(39.52)$ & 56 & $33(26.61)$ & 124 & $82(66.13)$ \\
\hline
\end{tabular}

Of the 82 malaria positive patients $84.15 \%$ (69) were diagnosed with Plasmodium falciparum infection and $8.54 \%$ (7) with Plasmodium malariae while $7.31 \%$ (6) of them were anonymous as they were identified only in thick films. Table 3 shows the frequency of distribution pattern of Plasmodium species causing malaria infection.

Table 3: Frequency of distribution pattern of Plasmodium species causing malaria infection

\begin{tabular}{l|cc}
\hline \multicolumn{1}{c|}{ Plasmodium species } & Frequency & Percentage (\%) \\
\hline Plasmodium falciparum & 69 & 84.15 \\
Plasmodium malariae & 7 & 8.54 \\
Anonymous & 6 & 7.31 \\
\hline Total & $\mathbf{8 2}$ & $\mathbf{1 0 0}$ \\
\hline
\end{tabular}

\section{Discussion}

The results from this study showed that out of 124 capillary blood samples collected, 82 (66.13\%) tested positive for malaria following Giemsa stain while $42(33.87 \%)$ were negative. This has been in accordance with most of the previous studies carried out in nearly all the sub-Saharan parts of African continent. It also agrees with the findings of the WHO (2004) that the disease is endemic in this region of the world. Some of the reasons associated with the high prevalence of malaria in this region include physical environment e.g. temperature, rainfall, collection of water etc., increase in agricultural colonization, construction of large economic projects such as dams and irrigation schemes, drug resistance, poor vector control, deterioration of health services, and cultivation of rice and cotton (Hommel and Gilles, 2006).

This study has shown that male patients constitute about $54.84 \%$ (68) with $39.52 \%$ (49) of the total positive samples. However, statistical analysis suggests that the distribution of malaria disease is independent of the gender of the patient ( $\mathrm{p}$-value $=0.1780$ ). This could be as a result of the fact that more male children were brought to the clinic on clinic days than female children. Results in table 1 show that the patients having the highest occurrence were from Wamakko Local Government with $28.23 \%$ (35). This could be as a result of their highest figure of attendance to Usmanu Danfodiyo University Teaching Hospital when compared with other Local Governments as 39.52\% (49) of the total patients studied were from there. That in turn could be due to the fact that UDUTH, the site where the samples were collected, is in 
Wamakko Local Government. Hence it is the closest health facility to the indigenous inhabitants of the Local Government Area. Dange Shuni Local Government was having $20.97 \%$ (26) of the distribution of malaria having a total attendant of $34.68 \%$ (43). It was second to Wamakko Local Government perhaps merely by virtue of the site of the sample collection being in Wamakko Local Government. Inhabitants of Dange Shuni might be a little further than the former to have equal attendants. It could be that for convenience reasons some attend other closer health facilities available. Sokoto South was the third highest in attendance as well as in occurrence of malaria with 20.97\% (26) and 12.10\% (15) respectively. Same reasons as in Dange Shuni Local Government could be ascribed to Sokoto South Local Government. It could also be that there are more available health facilities in their vicinity than Dange Shuni Local Government, hence the much difference in patients' attendance in UDUTH. Sokoto North Local Government has the least figure in attendance with $1.61 \%$ (2) hence the least occurrence of malaria was indexed there with $1.61 \%$ (2) according to this study. The least attendance registered there could be due to the fact that there are more secondary health facilities in Sokoto North (e.g. Specialist Hospital, Women and Children Welfare Clinic etc.) than in any of the other three Local Governments. However, on general basis, more than $50 \%$ of the patients from all the Local Governments turned out to be positive for malaria infection which in totality agrees with the established theories of malaria endemicity in this part of the world. Most, if not all of the factors highlighted by Snow and Gilles (2002) as contributory to malaria endemicity is obtainable in all the studied Local Governments. Such factors include rain, global warming, explosive growth of urban areas, arrival of non-immune émigré, agricultural development, availability of Anopheles mosquitoes, breakdown of health services, antimalarial drug resistance etc.

It is also shown that those children within the age range of $0-5$ year have the highest malaria infection with $58.06 \%$ (72). The other group within the age bracket of $6-10$ year have relatively lower infection rate of $8.07 \%$ (10). However, statistical analysis suggests that the distribution of the disease is independent of the age of the patients ( $\mathrm{p}$-value $=0.5759)$. This finding could be attributed to the fact that those patients aged $0-5$ years are more in attendance to the clinic on clinic days than the other age group. That could on the other hand, be attributed to the immunity strength of the patients with increase in age. This is supported by Hommel and Gilles (2006) where they mentioned that agedependency is a crucial feature of malaria immunity. It is also in accordance with the theory of Kayser et. al. (2005) that children in endemic regions aged 6 months to 3 years are most susceptible to infection. Table 3 shows the species identified in the 82 positive samples from the thin blood film. $84.15 \%$ (69) were P. falciparum, having the highest prevalence. P. malariae has $8.54 \%$ (7) as its prevalence in the study area. In some patients, the infection was usually mild; hence there was a very great chance of missing the parasite in the thin blood film. Thus, $7.31 \%$ (6) of the 82 total positive samples were anonymous, i.e. they were arbitrarily missed in the thin film. This finding was supported by Kayser et. al. (2005) who gave an estimated clinical case of malaria prevalence in sub-Saharan Africa with P. falciparum mostly indicated. P. vivax was not identified in any of the study subjects. This could be as a result of the absence of Duffy blood group antigen (Fy $\left.{ }^{\mathrm{a}} \mathrm{Fy} \mathrm{F}^{\mathrm{b}}\right)$ in the native population of West Africa. This is in accordance with the theory of Paniker (2007). P. ovale was also not identified in any of the study subjects. That could be due to the fact that it is the most infrequent of all plasmodia infecting human, though seen mostly in tropical Africa (Paniker, 2007).

\section{Conclusion}

This study has shown that malaria is prevalent among children living in Sokoto metropolis, perhaps even endemic in the region. It is also evident from the study that by 'Gold standard' method of Giemsa stain, P. falciparum is the most prevalent specie of plasmodium that causes malaria in Sokoto metropolis with $84.15 \%$, followed by P. malariae with $8.54 \%$. The other species are not incriminated in anyway with causation of malaria infection in Sokoto metropolis.

\section{Acknowledgement}

We would like to appreciate the help of Professor E. I. Ikeh, Professor D. E. Agbonlahor and Professor I. B. Enweani in this research work.

\section{References}

1. Cheesbrough M. (2000). District laboratory practice in tropical countries, part I. Low price edn. Cambridge (UK): Cambridge University Press.

2. Hommel M, Gilles H.M. (2006). Topley \& Wilson's microbiology \& microbial infections: Malaria. 10th ed. Edward Arnold (Publishers) Ltd.

3. Iman A. (2006). Prevalence of coliform bacteria on environmental surface in day care centres and nursery schools in Sokoto metropolis. MPH Dissertation, Usmanu Danfodiyo University Sokoto.

4. Jayaram Paniker C.K. (2007). Textbook of medical parasitology. 6th ed. New Delhi (India): Jaypee Brothers Medical Publishers (p) Ltd.

5. Jeffrey S. and Pia M. (2002). The economic and social burden of malaria. Nat J, 415, 680 - 685 . Available on:http://www.nature.com/nature/journal/v415/n6872/full/415680a.html

6. J. Ochei, A. Kolhatkar (2008). Medical laboratory science theory and practice. $7^{\text {th }}$ edn. New Delhi; Tata McGraw-Hill Publishing Company Ltd.

7. Kayser F.H., Kurt A. Bienz, Johannes Ec Kert, Rolf M. Zinkernagel (2005). Medical microbiology. 5th ed. New York; America. P. 521-6.

8. Snow R. W. and Gilles H. M. (2002). The epidemiology of malaria. In: Warrell, D. A. and Gilles, H. M. (eds), Essential malariology, 4th edn. London: Arnold, 85 - 106.

9. World Health Organization (2004). Scaling up home-based management of malaria from research to implementation. WHO/HTM/MAL/2004.1096. TDR/IDE/HMM/04.1 Roll-back Malaria Department/Unicef/UNDP/World Bank. WHO Special Programme for Research and Training in Tropical Diseases. 